STUDI

FRANCESI

\section{Studi Francesi}

Rivista quadrimestrale fondata da Franco Simone

Varia

\title{
GERMAINE DE STAËl, Correspondance générale, t. IX. Derniers Combats, 12 mai 1814-14 juillet 1817
}

\section{Lise Sabourin}

\section{OpenEdition}

Journals

Édition électronique

URL : http://journals.openedition.org/studifrancesi/16461

DOI : 10.4000/studifrancesi. 16461

ISSN : 2427-5856

Éditeur

Rosenberg \& Sellier

\section{Édition imprimée}

Date de publication : 1 juillet 2019

Pagination : 168

ISSN : 0039-2944

\section{Référence électronique}

Lise Sabourin, « Germaine de stä̈l, Correspondance générale, $t$. IX. Derniers Combats, 12 mai 1814-14 juillet 1817 », Studi Francesi [En ligne], 187 (LXIII | I) | 2019, mis en ligne le 01 juillet 2019, consulté le 25 janvier 2021. URL : http://journals.openedition.org/studifrancesi/16461 ; DOI : https://doi.org/ 10.4000/studifrancesi.16461

Ce document a été généré automatiquement le 25 janvier 2021.

\section{(c) (i) (9)}

Studi Francesi è distribuita con Licenza Creative Commons Attribuzione - Non commerciale - Non opere derivate 4.0 Internazionale. 


\title{
GERMAINE DE STAËl, Correspondance
} générale, t. IX. Derniers Combats, 12 mai 1814-14 juillet 1817

\author{
Lise Sabourin
}

\section{RÉFÉRENCE}

GERMAINE DE STAËl, Correspondance générale, t. IX. Derniers Combats, 12 mai 1814-14 juillet 1817, volume préparé par Stéphanie Genand et Jean-Daniel Candaux, Paris-Genève, Champion-Slatkine, 2017, 663 pp.

1 Publié dans la foulée du tome VIII, le tome IX de la Correspondance staëlienne est démuni d'avant-propos, étant déjà mentionné dans celui du volume précédent par Stéphanie Genand. Seul le calendrier staëlien de 1814 à 1817 (pp. XI-XVIII) précède donc les lettres de Mme de Staël revenue à Paris lors de la première Restauration le 12 mai 1814 pour y mener ses «Derniers Combats». Les cinq sections sont munies chacune d'une brève synthèse.

2 D'abord ce sont les «Retours» (Paris, Coppet, Paris, 13 mai 1814-6 mars 1815) après douze années d'exil. Mme de Staël trouve Paris bien changé: d'abord par la présence des troupes étrangères, puis par l'anéantissement de l'ancienne société, enfin par l'empreinte impériale qui a changé les mentalités. Quant à Coppet, il redevient pour elle un lieu de villégiature, dix ans après la mort de son père. Ralliée par raison à Louis XVIII, l'écrivain continue à entretenir des relations suivies avec Bernadotte; elle prépare par ailleurs le mariage d'Albertine avec Victor de Broglie, brillant mais sans fortune, ce qui l'oblige à toutes sortes de démarches pour se faire rembourser par le roi le dépôt à la nation effectué par son père.

3 Les «Cent-Jours» (12 mars 1815-27 septembre 1815) viennent interrompre ces dix mois de paix et d'angoisse mêlées. Outre le cauchemar de la proscription qui ressurgit, et sur le plan personnel la crainte de ne pas pouvoir doter sa fille, le retour de l'île d'Elbe lui 
fait redouter de nouvelles épreuves pour la France. Mais l'acte additionnel et l'aspect libéral adoptés par l'empereur de retour la rassurent un peu, quoiqu'elle se refuse à toute compromission et reste hermétique aux divers ralliements qu'ils suscitent durant ces «trois mois les plus malheureux de l'Histoire» française à ses yeux.

4 S'épargnant ensuite le spectacle de régression politique que constitue pour elle la domination ultra aussi bien que le poids étranger sur le gouvernement français, elle retourne en Italie qu'elle considère «Dans l'abîme du passé» (6 octobre 1815-20 juin 1816). C'est en effet pour elle «le pays du deuil» du fait de son séjour après la mort de Necker et par l'impression que lui donne la présence de grandes civilisations enfouies par comparaison aux petitesses du présent. Le mariage de sa fille est enfin célébré en février 1816 après la liquidation du dépôt grand-paternel, ce qui la réjouit, mais aussi l'en sépare, tandis que Rocca est de plus en plus atteint par la tuberculose.

«J'ai vu le genre humain...», écrit-elle, revenue à Coppet savourer son calme estival (23 juin 1816-9 juin 1817). Elle reçoit en fait beaucoup de visiteurs anglais, dont Byron qu'elle apprécie et soutient. Tout en déplorant les excès de la Terreur blanche en France, notamment contre les protestants, elle rédige ses Considérations sur la Révolution française.

6 Mais la maladie la rattrape et, malgré sa volonté de lutter - «Je vais tâcher de ne pas mourir» (Paris, 26 octobre 1816-9 juin 1817), elle sent venir sa fin. Elle reçoit pourtant toujours avec acharnement, notamment Wellington dont elle veut obtenir le retrait de ses troupes, et tâche d'agir aux côtés de son gendre en faveur des doctrinaires, persuadée qu'elle est que la France, quoique endettée, méfiante et ulcérée de l'occupation, est bien demeurée comme elle «fille de Necker et résistante à Napoléon». C'est ainsi en «hérétique et libérale» qu'elle meurt, paralysée par une fièvre bilieuse qui l'emporte, intéressée jusqu'au bout par les affaires du monde.

7 Aux habituels table des correspondants, bibliographie et index des noms s'ajoute un descriptif de ses domiciles parisiens durant cette période finale. 